\title{
Examining bias in pollen-based quantitative climate reconstructions induced by human impact on vegetation in China
}

\author{
Wei Ding ${ }^{1}$, Qinghai $\mathrm{Xu}^{2}$, and Pavel E. Tarasov ${ }^{1}$ \\ ${ }^{1}$ Institute of Geological Sciences, Palaeontology, Free University of Berlin, 12249 Berlin, Germany \\ ${ }^{2}$ Institute of Nihewan Archaeology, Hebei Normal University, Shijiazhuang 050024, China
}

Correspondence to: Qinghai Xu (xuqinghai@mail.hebtu.edu.cn)

Received: 24 April 2017 - Discussion started: 3 May 2017

Accepted: 29 August 2017 - Published: 28 September 2017

\begin{abstract}
Human impact is a well-known confounder in pollen-based quantitative climate reconstructions as most terrestrial ecosystems have been artificially affected to varying degrees. In this paper, we use a "human-induced" pollen dataset (H-set) and a corresponding "natural" pollen dataset (N-set) to establish pollen-climate calibration sets for temperate eastern China (TEC). The two calibration sets, taking a weighted averaging partial least squares (WA-PLS) approach, are used to reconstruct past climate variables from a fossil record, which is located at the margin of the East Asian summer monsoon in north-central China and covers the late glacial Holocene from $14.7 \mathrm{ka} \mathrm{BP}$ (thousands of years before AD 1950). Ordination results suggest that mean annual precipitation $\left(P_{\mathrm{ann}}\right)$ is the main explanatory variable of both pollen composition and percentage distributions in both datasets. The $P_{\text {ann }}$ reconstructions, based on the two calibration sets, demonstrate consistently similar patterns and general trends, suggesting a relatively strong climate impact on the regional vegetation and pollen spectra. However, our results also indicate that the human impact may obscure climate signals derived from fossil pollen assemblages. In a test with modern climate and pollen data, the $P_{\text {ann }}$ influence on pollen distribution decreases in the $\mathrm{H}$-set, while the human influence index (HII) rises. Moreover, the relatively strong human impact reduces woody pollen taxa abundances, particularly in the subhumid forested areas. Consequently, this shifts their model-inferred $P_{\text {ann }}$ optima to the arid end of the gradient compared to $P_{\text {ann }}$ tolerances in the natural dataset and further produces distinct deviations when the total tree pollen percentages are high (i.e. about $40 \%$ for the Gonghai area) in the fossil sequence. In summary, the calibration set
\end{abstract}

with human impact used in our experiment can produce a reliable general pattern of past climate, but the human impact on vegetation affects the pollen-climate relationship and biases the pollen-based climate reconstruction. The extent of human-induced bias may be rather small for the entire late glacial and early Holocene interval when we use a reference set called natural. Nevertheless, this potential bias should be kept in mind when conducting quantitative reconstructions, especially for the recent 2 or 3 millennia.

\section{Introduction}

Pollen analysis was initially developed 100 years ago for inferring past changes in vegetation and climate (von Post, 1916). Since the 1970s, quantitative reconstructions from biological proxies have made a revolutionary change to studies of the past climate (Imbrie and Kipp, 1971; Juggins, 2013). Numerical methods, such as the modern analogue technique (MAT; Overpeck et al., 1985), weighted averaging partial least squares (WA-PLS; ter Braak and Juggins, 1993), and others (Birks et al., 2010; Juggins and Birks, 2012), are widely used in pollen-based quantitative reconstructions (Guiot, 1990; Markgraf et al., 2002; Seppä et al., 2004; St. Jacques et al., 2008; Tarasov et al., 2011; Xu et al., 2010b). Pollen-based palaeoclimate reconstructions relay on modern pollen-climate relationship studies ( $\mathrm{Li}$ et al., 2009; Markgraf et al., 2002; Seppä et al., 2004; Shen et al., 2006) and pollen-climate data compilations (Bartlein et al., 2010; Prentice et al., 2000; Tarasov et al., 2005; Whitmore et al., 2005; Yu et al., 1998; Zheng et al., 2014). Thousands 
of modern pollen samples from bioclimatic regions all over the world have been collected and analysed, for example, in the framework of the BIOME6000 Project (Prentice et al., 2000). These pollen data have been used for testing the biome reconstruction method and regional sensitivity (e.g. Tarasov et al., 1998; Yu et al., 1998) and for quantitative climate reconstructions using statistical approaches. A methodological assumption that the ecological response of species does not change during the Quaternary based on Lyell's uniformitarianism (Scott, 1963) is implicit in these studies, and they require modern organism-environment relationships as calibration models (Birks et al., 2010; Juggins and Birks, 2012).

There are several types of uncertainties in reconstructing palaeoclimate from pollen data using calibration models (Guiot et al., 2009; Marquer et al., 2014; Parnell et al., 2016; Xu et al., 2016b). In China and other regions with longterm human occupation, biomes can be strongly modified rather than natural (Ren and Beug, 2002; Zhang et al., 2010). The question of how well modern samples reflect the natural vegetation thus needs to be addressed (Xu et al., 2010a). It is most likely that modern pollen-climate relationships in such regions after a long-lasting human impact are different from what they were in the past. For example, comparing the performance of pre-disturbance (1895-1924) and modern (1961-1990) pollen-climate calibration sets from Minnesota, St. Jacques et al. (2008) found that the pre-settlement model performs better than the modern one in reconstructing past climate. The human impact on the terrestrial vegetation over the past 150 years in the American Mid-west is thus apparent in the modern calibration set. Such a distortion in the modern pollen dataset can generate bias in the climate reconstruction for those regions (Li et al., 2014; St. Jacques et al., 2015, 2008; Tian et al., 2017). Palynologists therefore have to face this challenge in vegetation and climate reconstructions when using pollen data from densely populated regions (Juggins and Birks, 2012; Seppä et al., 2004; Tarasov et al., 1999; Xu et al., 2010a).

In China, rich archaeological evidence suggests that crop domestication may have taken place in the early Holocene or even earlier (Bestel et al., 2014; Lu et al., 2009; Zhao and Piperno, 2000), and enhanced farming practices have been reported since 8000 years ago (Liu et al., 2015; Lu et al., 2009; Zhao, 2011). Early agriculture was usually accompanied by slash-and-burn clearance of forest patches (Ruddiman, 2003), and pollen-inferred anthropogenic impacts on natural vegetation are noted from as early as 6000 years ago in eastern China (Ren and Beug, 2002; Wang et al., 2010). Due to growing demand for land, construction materials, and fuel, disturbances to the natural vegetation over the last 2 millennia occurred widely and are commonly detected in the pollen records (Cao et al., 2010; Ni et al., 2014; Xu et al., 2016a; Zhao et al., 2010, 2009). Consequently, human impact in both the modern reference datasets and the fossil pollen records needs to be considered when reconstructing past climate from pollen. In China, in contrast to North
America, it is not possible to establish a calibration set consisting of pre-settlement pollen and climate data. However, it is still important to estimate what kind of bias may appear in pollen-based quantitative climate reconstructions using Chinese pollen data.

In the past 2 decades, a number of modern pollen studies have been conducted in China to investigate regional pollenvegetation-climate relationships (Herzschuh et al., 2010; Li et al., 2009; Lu et al., 2011; Luo et al., 2009; Shen et al., 2006; Xu et al., 2007; Zhang et al., 2012; Zheng et al., 2008) and human impact on vegetation (Ding et al., 2011; Liu et al., 2006; Pang et al., 2011; Wang et al., 2009; Yang et al., 2012; Zhang et al., 2014, 2010). At the same time, representative modern reference datasets (Cao et al., 2014; Xu et al., 2010a; Yu et al., 2000; Zheng et al., 2008, 2014) and fossil pollen datasets (Cao et al., 2013; Ren and Beug, 2002; Sun et al., 1999) have been assembled, which make it possible to reconstruct the vegetation and climate for individual sites, regions, or the of whole China (Chen et al., 2015; $\mathrm{Ni}$ et al., 2014; Tian et al., 2016; Wang et al., 2014; Xu et al., 2010b). Despite the aim of these studies to use modern surface samples from natural (i.e. likely undisturbed) vegetation communities for establishing their calibration datasets and to exclude samples representing human-disturbed vegetation communities (Zheng et al., 2014), the presence in the datasets of some samples from eastern China referred to as "troublesome" due to intense human impact surrounding the vegetation patches (Xu et al., 2010a) suggests that the problem was not completely resolved. Li et al. (2014) assessed the reference pollen data in the currently available datasets from central-eastern China using a human influence index (HII) and concluded that surface samples are biased due to significant human impact on the natural vegetation. Pollen-based climate reconstructions for the late Holocene in this region would thus also be biased.

Obtaining reliable climate reconstructions in regions with a long history of human activities is indeed a big challenge but also an important scientific task. For example, reconstructing rainfall in temperate eastern China (TEC) is not only necessary for understanding the East Asian summer monsoon (EASM) variations (Chen et al., 2015; Guiot et al., 2008; Wen et al., 2013; Xu et al., 2010b), but also very important when studying human adaptation to climate change and the origins of agriculture and cultural evolution ( $\mathrm{Lu}$ et al., 2009; Mu et al., 2015; Tarasov et al., 2006). In this paper, we (1) compiled a human-induced training set with 791 surface pollen spectra and a corresponding natural training set with 806 spectra from TEC, (2) compared the pollen-climate model performances of the two calibration sets, (3) investigated the deviations in the reconstructed results for a fossil record based on each calibration set, and (4) discuss the mechanism of bias caused by human impact. 


\section{Regional setting}

Temperate eastern China (TEC; $30-53^{\circ} \mathrm{N}, 100-135^{\circ} \mathrm{E}$ ) was chosen as the study area for its ecological sensitivity to climate change (e.g. forest-steppe boundary shifts with EASM variations) and long-term human impact on vegetation (Guiot et al., 2008; Liu et al., 2014; Ren, 2000; Xiao et al., 2004). The region extends from the eastern margin of the Tibetan Plateau (TP) to the Yellow Sea coastline and from the northern catchment of the Yangtze River to the Heilong (Amur) River, covering about one-third of China (Fig. 1a). Topographically, it encompasses three distinct levels, showing a decrease in elevation from the TP margin (2000-4000 m) to the Inner Mongolian plateau, Loess Plateau, Qin Mountains, Taihang Mountains, and Greater Khingan Mountains $(1000-2000 \mathrm{~m})$ and to the eastern hilly areas and flood plains $(<200-500 \mathrm{~m})$. The south-eastern part of the study area is dominated by EASM, while the north-western part is influenced by the westerlies (Fu et al., 2008). From the coast inland, mean annual precipitation $\left(P_{\mathrm{ann}}\right)$ varies from 1400 to $35 \mathrm{~mm}$, covering the conventional humid, subhumid, semiarid, and arid areas, and mean annual temperature $\left(T_{\mathrm{ann}}\right)$ decreases from 18 to $-6^{\circ} \mathrm{C}$ from south to north (Domrös and Peng, 1988).

Due to the large climatic and topographic gradients, several large-scale natural vegetation regions have been described for the study area (Fig. 1): (I) cold temperate needleleaf deciduous forest region, (II) temperate mixed needleleaf and deciduous broadleaf forest region, (III) warm temperate deciduous broadleaf forest region, (VI) temperate steppe region, (IVAi) northern subtropical broadleaf evergreendeciduous forest zone, (VIIBi) temperate semi-shrub and shrub desert zone, and (VIIIAi) subalpine scrub and alpine meadow zone (Editorial Committee of Vegetation Map of China, 2007; Wu et al., 2013). However, many natural ecosystems have been intensely modified by settlements and agricultural land use. For example, in 2015, forest coverage in the supposedly densely forested north-east of China was about $41 \%$ and only $26 \%$ in the warm temperate forest region, according to data from the China National Bureau of Statistics (http://data.stats.gov.cn).

\section{Materials and methods}

\subsection{Surface pollen data}

We use pollen data from a number of studies attempting to detect human-induced changes in surface pollen assemblages, including 43 spectra from the Anyang area in the central China Plain (Wang et al., 2009), 12 from the eastern Hexi Corridor (Ma et al., 2009), 78 from warm temperate hilly areas (Ding et al., 2011), 88 from the Hebei Plain and adjacent mountain area (Pang et al., 2011), 13 from south-east China (Yang et al., 2012), and 105 spectra from north-east China (Li et al., 2012, 2015). Additionally, 70 un- published spectra from the coastal plain between the Yellow River and the Yangtze River were generated for the purpose of this study. The samples were mostly collected from croplands, abandoned croplands, economic gardens and forests, pasturelands, and roadside scrub and woodlands. The field sampling strategies, laboratory procedures, analytical methods, pollen taxa, and other detailed information are described in the aforementioned studies. Additionally, we make use of some reference pollen datasets partly or entirely covering the study area (Wen et al., 2013; Xu et al., 2010a, 2007; Zheng et al., 2008), which were used to represent natural vegetation communities.

Samples from the different natural vegetation communities were integrated into a natural dataset $(\mathrm{N}$-set), while samples from human-induced vegetation or vegetation patches obviously disturbed by human activities were integrated into a human-induced dataset (H-set; Fig. 1b). We used reference samples from an approximate extent of $31-51^{\circ} \mathrm{N}$ and $102-130^{\circ}$ E with a sufficiently large $P_{\text {ann }}$ gradient of 150 $1100 \mathrm{~mm}$ and a $T_{\text {ann }}$ gradient of -3 to $16^{\circ} \mathrm{C}$ in order to cover the greatest possible climate range likely to be encountered in the fossil pollen record (see Sect. 3.3). Pollen percentages were recalculated based on the sum of terrestrial taxa. It should be clearly noted that pollen from cereal-type Poaceae and other distinct cultivated taxa (e.g. Brassica, Gossypium, Sesamum, and Linum) identified in the H-set (Ding et al., 2011; Li et al., 2015) were excluded to reduce anthropogenic noise. This strategy is similar to the one excluding aquatic pollen and spores in order to better catch the climatic signal. Finally, 806 spectra and 151 taxa form the $\mathrm{N}$-set, and 791 spectra and 147 taxa form the $\mathrm{H}$-set. The $\mathrm{N}$-set includes 11 samples from vegetation region I, 61 from region II, 300 from region III, 351 from region VI, 25 from region IVAi, 51 from region VIIBi, and 7 from region VIIIAi, while 14 samples from region I, 11 from region II, 433 from region III, 292 from region VI, and 41 from region IVAi appear in the H-set.

\subsection{Modern climate and human influence index data}

Mean monthly climate averages were derived from the latest available observation data (1981-2010) from 1208 welldistributed meteorological stations across the study area (Fig. 1a). The original data can be accessed from the China National Meteorological Information Center (http:// data.cma.cn). Mean values of annual precipitation $\left(P_{\mathrm{ann}}\right)$ and temperature $\left(T_{\mathrm{ann}}\right)$ and the mean temperature of the coldest $\left(\mathrm{Mt}_{\mathrm{co}}\right)$ and warmest month $\left(\mathrm{Mt}_{\mathrm{wa}}\right)$ were selected as the transfer function variables. These four climate parameters were estimated for each pollen site with the Polation 1.1 software (http://polsystems.rits-palaeo.com). A vertical lapse rate of $0.6^{\circ} \mathrm{C} / 100 \mathrm{~m}$, as suggested for China (Domrös and Peng, 1988), was applied and leave-one-out cross validation was used to assess the interpolation accuracy. Correlation coef- 


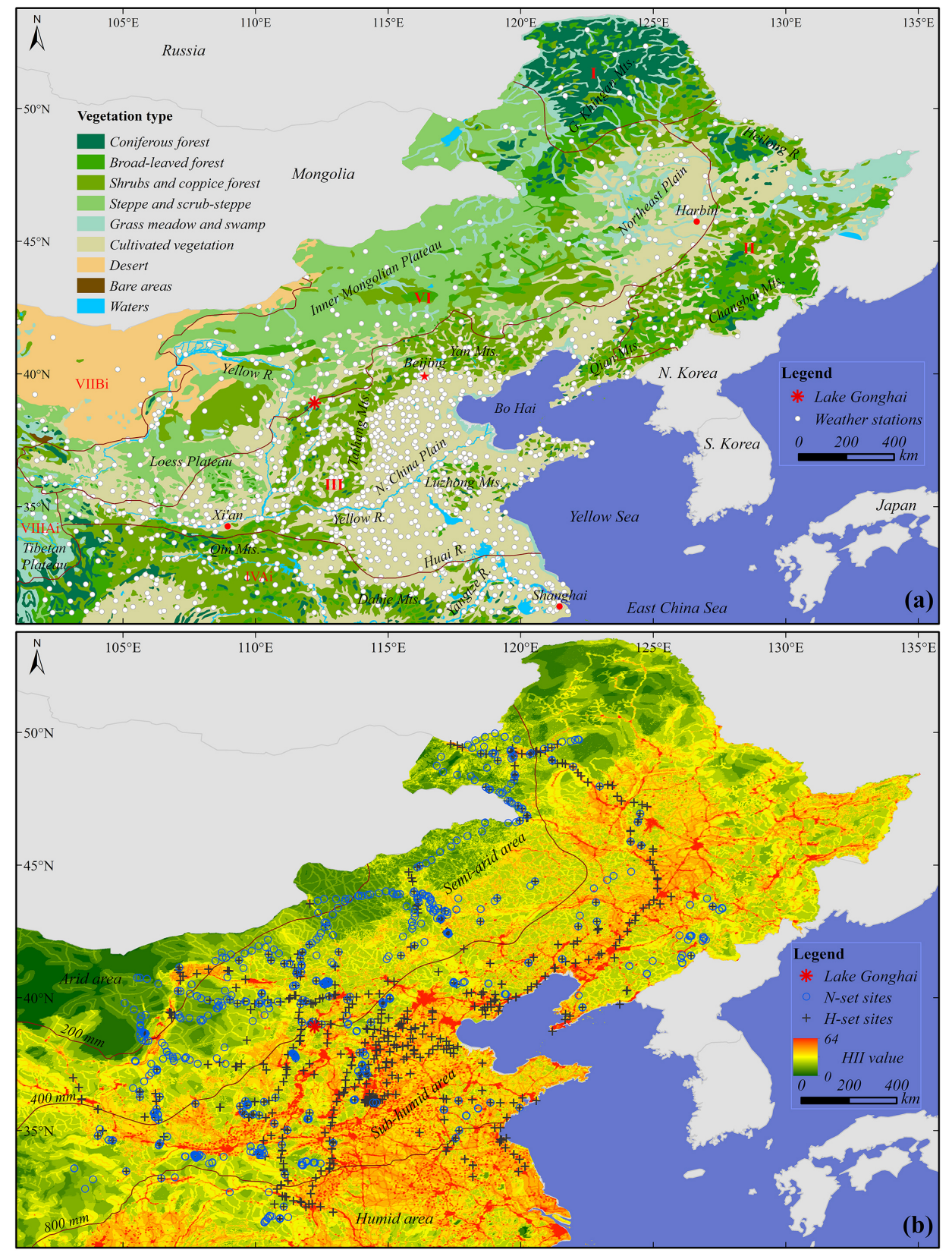

Figure 1. Maps of the study region showing the distributions of (a) vegetation regions and types, the 1208 meteorological stations, and (b) HII values with surface pollen sampling sites for the N-set (circles) and H-set (crosses). Selected large cities (red pentagram and dots), mountains (Mts.), rivers (R.), isohyets of 200, 400, and $800 \mathrm{~mm}$ (for annual precipitation), and the location of Lake Gonghai are marked.

ficients $(R)$ between estimated and observed climatic values of $0.97-0.99$ suggest that the results are robust.

Sanderson et al. (2002) developed a human influence index (HII) dataset for mapping the areas with and without a human footprint. The HII dataset quantifies human influence on terrestrial ecosystems based on four proxies (nine datasets), including human population pressure (population density), land transformation (land use/cover, roads and railways, built-up centres, settlements), accessibility (roads and railways, coastlines, navigable rivers), and electrical power infrastructure (night-time lights). Each of the nine datasets assigns a score from 0 to 10 according to a rating (or alternatively in a single score and 0 ) to assess human influence on $1 \mathrm{~km}^{2}$ of land surface. Sum scores from nine datasets were standardized as HII values, which range from 0 to 64 (WCS/CIESIN, 2005), with higher values indicating a higher degree of human impact (Fig. 1b). HII reflects only modern human impact and does not consider the human impact dur- 


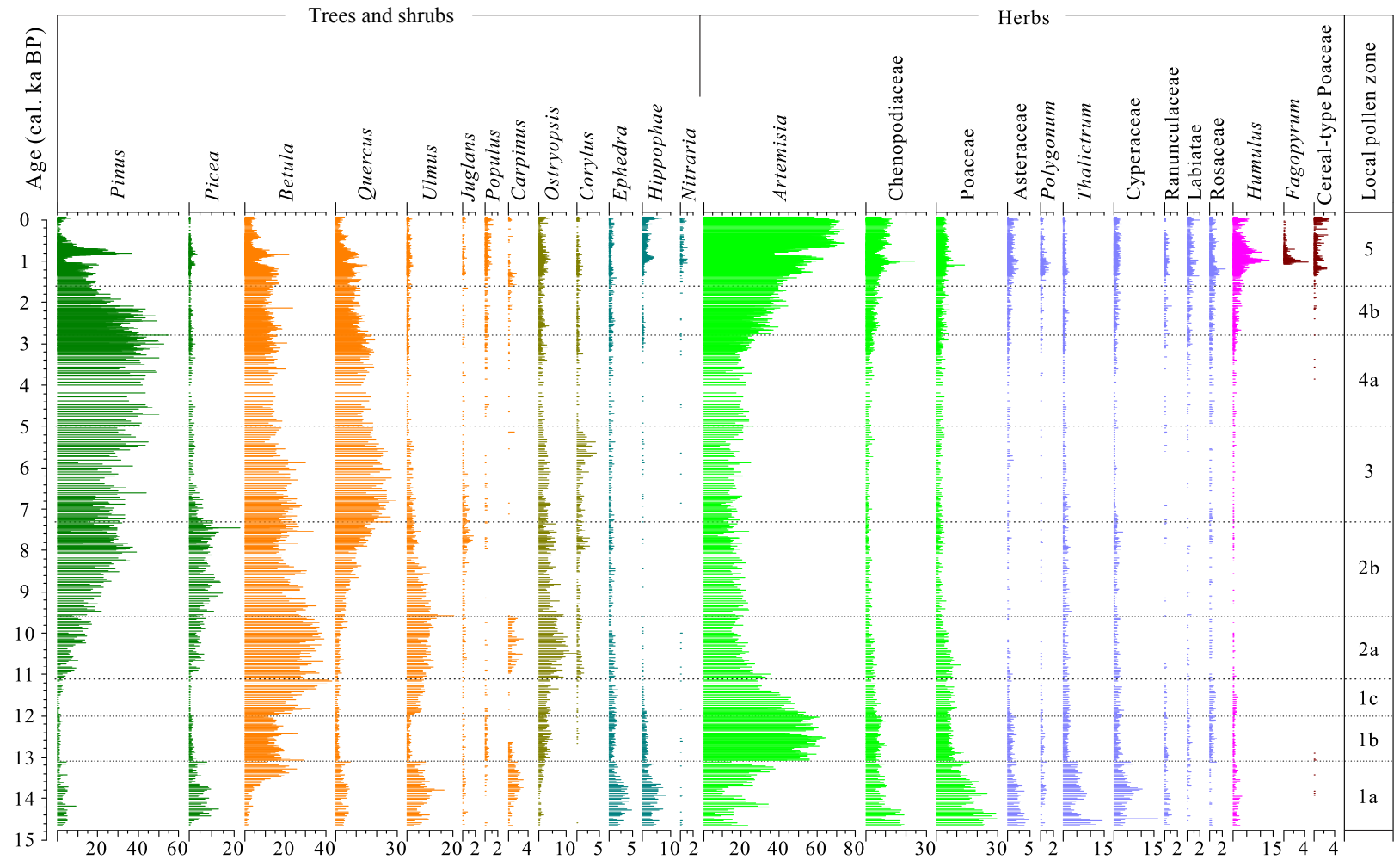

Figure 2. Simplified pollen percentage diagram of core GH09B from Lake Gonghai. The local pollen zone (and subzone) boundaries are based on the results of a constrained cluster analysis with the CONISS programme in Tilia software (Grimm, 1987, 2011) used to make the pollen diagram. The detailed information on vegetation succession was presented in Xu et al. (2016a).

ing the past. The HII has been recently employed to assess human influence on pollen assemblages in China ( $\mathrm{Li}$ et al., $2014,2015)$. In this study, HII values at $1 \mathrm{~km}^{2}$ grids are assigned to modern pollen reference sites using ArcGIS.

\subsection{Fossil pollen record from Lake Gonghai}

Lake Gonghai $\left(38^{\circ} 54^{\prime} \mathrm{N}, 112^{\circ} 14^{\prime} \mathrm{E}, 1860 \mathrm{~m}\right.$ above mean sea level) is a small $\left(0.18 \mathrm{~km}^{2}\right)$ hydrologically closed alpine lake with a water supply mainly from summer precipitation (Chen et al., 2015). It is located on the north-east margin of the Loess Plateau (Fig. 1). The lake lies close to the modern EASM border in the forest-steppe ecotone and experiences subhumid to semi-arid transitional moisture conditions. The upper $9.42 \mathrm{~m}$ of a core, GH09B, from Lake Gonghai was subsampled at $1 \mathrm{~cm}$ intervals for pollen analysis. Twenty-five (including seven from parallel core GH09C) accelerator mass spectrometry (AMS) ${ }^{14} \mathrm{C}$ dates of terrestrial plant macrofossils and $35{ }^{210} \mathrm{~Pb} /{ }^{137} \mathrm{Cs}$ dates of the uppermost $0.35 \mathrm{~m}$ of the lake sediment were used to establish a robust age-depth model (Chen et al., 2015; Xu et al., 2016a).

Vegetation succession in the area around Lake Gonghai has experienced five major stages during the last $14.7 \mathrm{kyr}$ (Fig. 2). Open forests and upland meadows dominated during the last deglaciation (14.7-11.1 ka), and abrupt strengthen- ing of Artemisia-dominated mountain steppe association occurred during 13.1-12.0 ka BP. In the early Holocene (11.1$9.6 \mathrm{ka})$, Betula, Carpinus, Ostryopsis, and Ulmus as pioneer tree species spread into the landscape. Later (9.6$7.3 \mathrm{ka}$ ) mixed forest dominated by Picea and Betula started to play a greater role. Temperate deciduous trees (e.g. Quercus) widely expanded and the mixed broadleaf-conifer forest grew around the lake during the Holocene climatic optimum (7.3-5.0 ka BP). The break-up of the climax community started from $5.0 \mathrm{kaBP}$ with the increasing of Pinus and the decreasing of Quercus and Betula percentages. A major increase in herbaceous pollen percentages occurred since $2.8 \mathrm{kaBP}$, especially during the last $1.6 \mathrm{kyr}$ when Humulus (including Urtica), Fagopyrum, and cereal Poaceae pollen types related to human activities became most prominent in the diagram (Fig. 2; Xu et al., 2016a). The vegetation dynamic inferred from the GH09B pollen sequence is a valuable source of environmental information for the EASM margin (Chen et al., 2015). In the current study, we selected this well-dated and high-resolution fossil record to reconstruct past climate using both the $\mathrm{N}$-set and $\mathrm{H}$-set of modern pollen as calibration sets. 

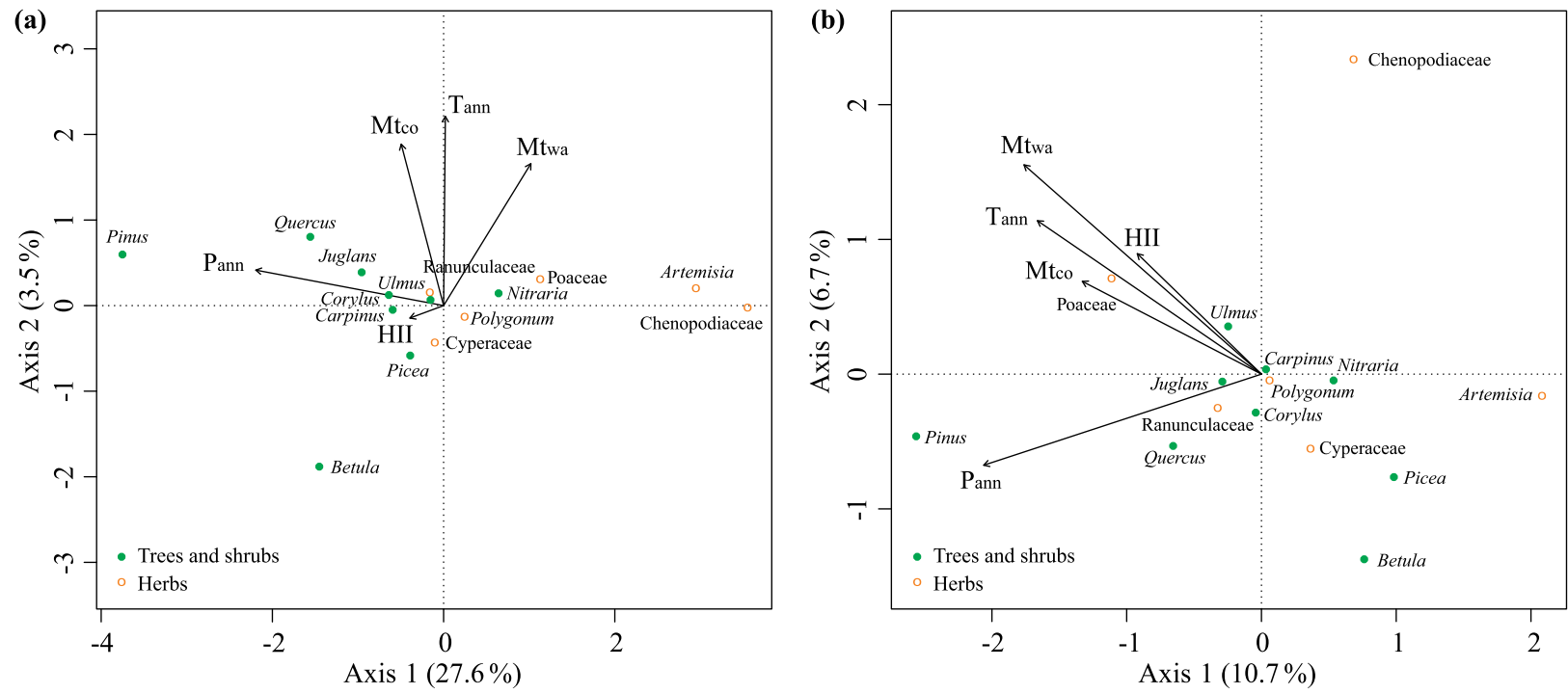

Figure 3. Ordination results of redundancy analysis (RDA) for 15 major pollen taxa with climate variables $\left(P_{\mathrm{ann}}, T_{\mathrm{ann}}, \mathrm{Mt}_{\mathrm{co}}\right.$, and $\left.\mathrm{Mt}_{\mathrm{wa}}\right)$ and human influence index (HII) for (a) the natural set and (b) the human-induced set.

\subsection{Numerical analyses}

Relationships between surface pollen spectra and climate variables are assessed by ordination techniques. To stabilise the variance and optimise the signal-to-noise ratio in the data, pollen taxa which occur in at least three samples and contribute $\geq 3 \%$ in at least one sample were selected and squareroot transformed for further analyses (Prentice, 1980). The length of the first axis in detrended correspondence analysis (DCA; Hill and Gauch, 1980) was used to determine whether redundancy analysis (RDA) or canonical correspondence analysis (CCA) should be chosen for the constrained ordination (ter Braak and Prentice, 1988). The ratio of the constrained eigenvalue to the first unconstrained eigenvalue $\left(\lambda_{1} / \lambda_{2}\right)$ for a climate variable is used to assess its potential to be reconstructed (ter Braak, 1987). A value of $\lambda_{1} / \lambda_{2}$ greater than 1 suggests that the variable is the main determinant in the dataset; otherwise, the reconstruction of the variable should be conducted with caution (Juggins, 2013).

HII was also analysed in the same way to evaluate the human impact on the pollen data and the quality of the training set. As HII is an environmental variable with certain stochastic features in locations and intensity, there is no robust ecological basis to estimate the optima and tolerance for a pollen taxon using any pollen-HII calibration set. Therefore, we used an indirect method to assess the potential bias induced from the training set due to human impact on surface samples. At first, we found five closest modern analogues for each fossil sample using MAT (Simpson, 2007) and then used the mean HII value at the analogue sites to examine the human influence on the analogue samples and to evaluate the bias in climate reconstruction for that given fossil sample.
The WA-PLS approach combines the virtues of the WA method to model ecological optima of species and the PLS method to select linear components from biological assemblages (ter Braak and Juggins, 1993). It has been tested along with the WA, MAT, and pollen response surface method (PRS) for eastern China data and demonstrated to give better results (Cao et al., 2014; Xu et al., 2010b) due to its generally good performance under non-analogue situations and its ability to cope with spatial autocorrelation (Cao et al., 2014; Juggins and Birks, 2012). The optimal number of WA-PLS components was selected using a randomization $t$ test (van der Voet, 1994). Low root mean squared error of prediction (RMSEP), low average and maximum biases, a high coefficient of determination $\left(R^{2}\right)$ between the predicted and observed climate values, and a rule-of-thumb threshold of $5 \%$ (reduction in RMSEP for adding a component) were all considered when selecting a model (Birks, 1998; Birks et al., 2010; Juggins and Birks, 2012).

The significance of the obtained reconstructions was also tested. The proportion of variance in the fossil sequence explained by 999 transfer functions trained with random data was calculated from a constrained ordination (Telford and Birks, 2011). To help understand the bias mechanism of the human impact on pollen assemblages, we estimated the WA optima and tolerances (Birks et al., 1990; ter Braak and Looman, 1986) of selected climate variables for major taxa. All numerical analyses were performed using vegan version 2.3-5 (Oksanen et al., 2016), analogue version 0.170 (Simpson, 2007), rioja version 0.9-5 (Juggins, 2015), and palaeoSig version 1.1-3 (Telford, 2015) in the R 3.2.4 environment (R Core Team, 2016). 

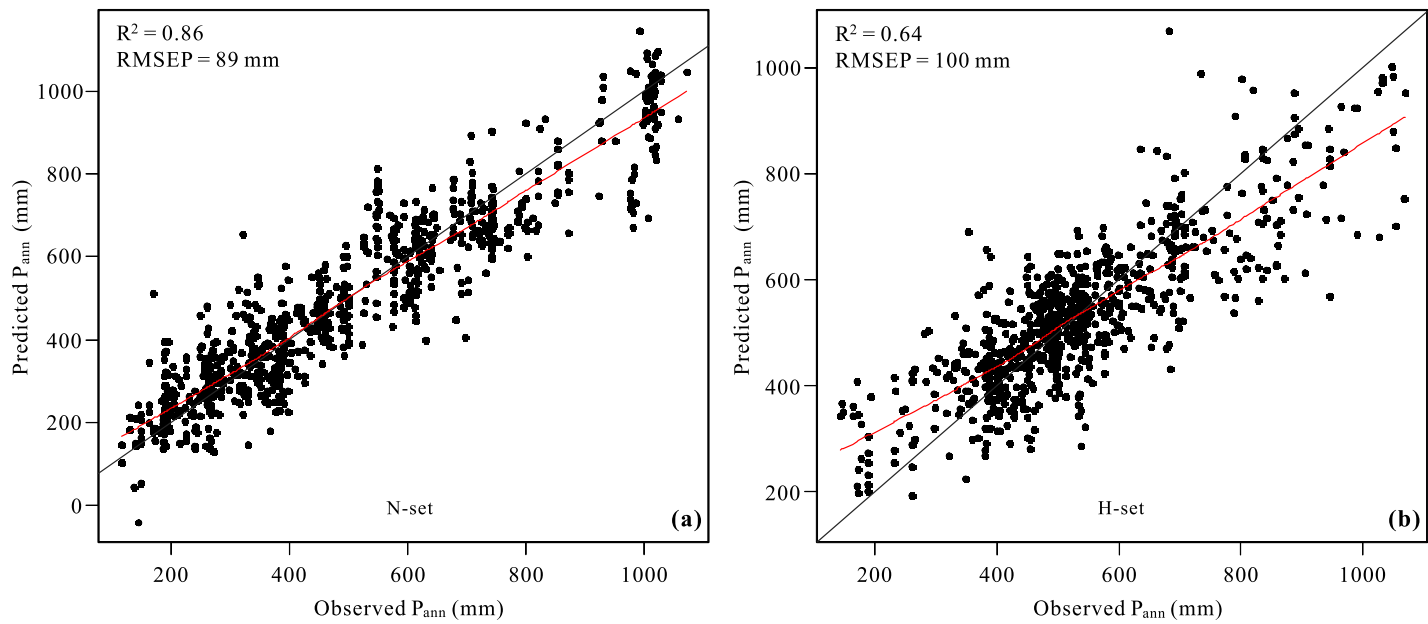

Figure 4. Scatter plots of pollen-based predicted annual precipitation $\left(P_{\text {ann }}\right)$ and observed $P_{\text {ann }}$ using two-component weighted averaging partial least squares (WA-PLS) models for (a) the natural set and (b) the human-induced set.

Table 1. Summary statistics for redundancy analysis (RDA) with pollen species and climate variables (annual precipitation $P_{\text {ann }}$, mean annual temperature $T_{\mathrm{ann}}$, mean temperature of the coldest month $\mathrm{Mt}_{\mathrm{co}}$, mean temperature of the warmest month $\mathrm{Mt}_{\mathrm{wa}}$ ) and the human influence index (HII). Sole expl (\%) is the pollen variance explained by variables as a sole predictor; marg expl (\%) is the marginal contribution of this variable in the model with all other variables. All $P$ values are 0.001 (based on 999 unrestricted Monte Carlo permutations).

\begin{tabular}{lrrr|rrr}
\hline Variables & \multicolumn{3}{c|}{ Natural dataset } & \multicolumn{3}{c}{ Human-induced dataset } \\
\cline { 2 - 6 } & $\lambda_{1} / \lambda_{2}$ & Sole expl (\%) & Marg expl (\%) & $\lambda_{1} / \lambda_{2}$ & Sole expl (\%) & Marg expl (\%) \\
\hline$P_{\text {ann }}$ & 1.28 & 20.14 & 10.56 & 0.34 & 6.31 & 5.85 \\
$T_{\text {ann }}$ & 0.08 & 2.83 & 1.20 & 0.26 & 5.57 & 1.55 \\
$\mathrm{Mt}_{\mathrm{co}}$ & 0.11 & 3.49 & 1.23 & 0.18 & 3.90 & 1.43 \\
$\mathrm{Mt}_{\mathrm{wa}}$ & 0.21 & 6.35 & 1.37 & 0.31 & 6.62 & 1.44 \\
$\mathrm{HII}$ & 0.03 & 1.12 & 0.76 & 0.10 & 2.29 & 0.55
\end{tabular}

\section{Results}

\subsection{Relationship between modern pollen and climate}

Ordinations are based on square-root-transformed pollen data of 99 taxa in the $\mathrm{N}$-set and 93 taxa in the H-set after noise reduction. DCA showed that the length of the first axis is $2.65 \mathrm{SD}$ (standard deviation units) in the N-set and 2.36 SD in the H-set, suggesting that linear ordination techniques (e.g. RDA) are appropriate to present the distribution of pollen taxa along the climate gradients in our datasets. When using each of the climatic variables as a sole predictor, $P_{\text {ann }}$ explains $20.56 \%$ (highest) of the pollen assemblage variance in the $\mathrm{N}$-set, while the thermal variables have much lower explanatory power $\left(T_{\mathrm{ann}}: 2.83 \%, \mathrm{Mt}_{\mathrm{co}}: 3.49 \%, \mathrm{Mt}_{\mathrm{wa}}: 6.35 \%\right)$. For the H-set, $P_{\text {ann }}$ explains $6.31 \%$, which is slightly less than $\mathrm{Mt}_{\mathrm{wa}}(6.62 \%)$. If we assess the marginal contribution of a variable after partialling out the interaction effect of other variables in an RDA, $P_{\text {ann }}$ explains the highest amount of variance in both the $\mathrm{N}$-set $(10.56 \%)$ and the $\mathrm{H}$-set $(5.85 \%)$. HII explains more variance in the $\mathrm{H}$-set $(2.29 \%)$ than in the $\mathrm{N}$-set $(1.12 \%)$ and has a marginal contribution of $0.55 \%$ in the H-set and $0.76 \%$ in the N-set. $P_{\text {ann }}$ has the highest $\lambda_{1} / \lambda_{2}$ ratio in both the $\mathrm{N}$-set (1.28) and the H-set (0.34); the $\lambda_{1} / \lambda_{2}$ ratios for all thermal variables and HII are much lower than 1 (Table 1). To better illustrate the modern pollen-climate relationships and their difference between natural and humanimpact scenarios, 15 major pollen taxa, which are also identified in the GH09B fossil sequence (Fig. 2), were selected to reveal the relationship between modern pollen and climate (Fig. 3). It seems that the general pattern of tree and shrubherb group separation is maintained, but the relationship of some pollen taxa (e.g. Picea, Betula, Poaceae, and Chenopodiaceae) with climatic variables (e.g. $\left.P_{\text {ann }}\right)$ is altered by human influence. The greater ordination difference in Poaceae and Chenopodiaceae in the two sets indicates that these two taxa are more sensitive to human impact. Our ordination results suggest that $P_{\text {ann }}$ is the main determinant of pollen distribution in TEC, and $P_{\text {ann }}$ in the N-set is used to establish a standard calibration set. We then use the H-set to establish a contrasting pollen- $P_{\text {ann }}$ calibration set to compare the deviation in the reconstructions and to see the extent of the poten- 
tial bias induced from human impact on the modern pollen assemblages.

\subsection{Test of the WA-PLS models}

A two-component WA-PLS model performed best with the lowest RMSEP and highest $R^{2}$ for the $\mathrm{H}$-set, and the best performer was a three-component model for the $\mathrm{N}$-set (Table 2). However, the improvement ( $1.48 \%$ reduction in RMSEP) over the two-component model was less than the threshold of $5 \%$ and not significantly different $(P=0.098)$, and therefore we selected a two-component WA-PLS model for both datasets. The $R^{2}$ between predicted $P_{\text {ann }}$ values and observed values in the N-set is 0.86 and the RMSEP is $89 \mathrm{~mm}$. Both are better than those for the H-set $\left(R^{2}=0.64\right.$; RM$\mathrm{SEP}=100 \mathrm{~mm}$; Fig. 4). The percentage of RMSEP to the sampled $P_{\text {ann }}$ gradient $(940 \mathrm{~mm})$ for the $\mathrm{N}$-set is $9.47 \%$ and for the H-set $(927 \mathrm{~mm}) 10.79 \%$. Overestimates at the low end of the $P_{\text {ann }}$ gradient (i.e. for sites from arid areas) and underestimates at the high end (sites from humid areas), which is an inevitable systematic bias in all WA-based models referred to as an "edge effect", are larger in the H-set than in the N-set.

\subsection{Annual precipitation $\left(P_{\text {ann }}\right)$ reconstructions for Lake Gonghai}

We applied the pollen- $P_{\text {ann }}$ WA-PLS models to the Lake Gonghai fossil record (Chen et al., 2015; Xu et al., 2016a). The proportion of the variance in the fossil data explained by the first PCA axis is $47.79 \%$, and the significance tests suggest that $41.57 \%$ of the variance in the $\mathrm{N}$-set can be explained by $P_{\text {ann }}(P=0.001)$ and $23.32 \%$ for the $\mathrm{H}$-set $(P=0.033$; Fig. 5). The two calibration sets produced very similar reconstructed $P_{\text {ann }}$ patterns (including major trends and change points) but with distinct deviations in their values (range: -105 to $95 \mathrm{~mm}$ and $\mathrm{SD}=46 \mathrm{~mm}$ ) most of the time (Fig. 6a). The deviation is calculated as the reconstructed N-set $P_{\text {ann }}$ value minus the corresponding $\mathrm{H}$ set $P_{\text {ann }}$ value (Fig. $6 \mathrm{~b}$ ). From the deviation pattern, six zones or time windows (TWs) are demarcated. From 14.7 to $13.1 \mathrm{ka} \mathrm{BP}$ (TW1), the deviation decreases gradually from -70 to $20 \mathrm{~mm}$. During 13.1-12 ka BP (TW2), the deviation fluctuates between -30 and $30 \mathrm{~mm}$ and the mean value for this period is only $3 \mathrm{~mm}$. The deviation varies from -20 to $100 \mathrm{~mm}$ and generally appears to increase in the 12.0 $7.3 \mathrm{kaBP}$ interval (TW3). A downward trend can be observed starting from $7.3 \mathrm{ka} \mathrm{BP}$ (TW4), and the deviation decreases from a relative stable value of $75 \mathrm{~mm}$ to around zero ( $\pm 35 \mathrm{~mm}$ ) during 2.8-1.6 ka BP (TW5). In the most recent period (TW6), the deviation is mostly negative with a mean value of $-40 \mathrm{~mm}$. The deviation curve over the last $14.7 \mathrm{kyr}$ generally correlates $(R=0.81)$ with the tree pollen percentage curve (Fig. 6c).

\subsection{WA optima estimates and analogue measures}

The WA optima and tolerances of 15 major pollen taxa in both the $\mathrm{N}$ - and $\mathrm{H}$-sets were estimated (Fig. 7). The optima for $P_{\text {ann }}$ for most tree taxa (Picea, Pinus, Betula, Quercus, Carpinus, Juglans) and for Corylus (representing shrubs and small trees) in the $\mathrm{H}$-set are shifted to drier conditions compared to those in the N-set. For most herbaceous taxa (Chenopodiaceae, Polygonum, Poaceae, Artemisia, Ranunculaceae) and the drought-enduring shrub Nitraria, the optima are shifted towards wetter conditions. Ulmus (a commonly cultivated tree) and Cyperaceae (species-rich herbaceous taxon) are exceptions in the arboreal and non-arboreal groups, respectively. The estimated range of tolerance in the $\mathrm{H}$-set is compressed for most taxa in comparison to the $\mathrm{N}$ set, especially for tree taxa, which shrink by about $18-55 \%$ (Fig. 7). The mean HII values of the five best modern analogues in the $\mathrm{H}$-set are generally higher than those in the $\mathrm{N}$ set, except for 13.1-12 ka BP and the last $1.6 \mathrm{kyr}$ period when they are relatively close; both are low for the mid-Holocene fossil samples (Fig. 6d).

\section{Discussion}

\subsection{Climatic signals in pollen assemblages obscured by human impact}

The pollen record is a complex and non-linear function of vegetation, which in turn is a function of climate based on some key assumptions (Birks et al., 2010). The big challenge for pollen-based climate reconstructions is that this indirect pollen-climate relationship can be affected by several other (non-climatic) factors, for example, by human activities (Birks and Seppä, 2004; Ren, 2000; Xu et al., 2010b). RDA results show that the ability of $P_{\text {ann }}$ to explain pollen variance declines a lot in the $\mathrm{H}$-set in comparison to the $\mathrm{N}$ set (Table 1). The statistical performance of WA-PLS for the $\mathrm{H}$-set is poorer (Table 2), suggesting that climatic signals in the $\mathrm{H}$-set have been partly obscured by human impact. Due to agricultural land use and human-induced deforestation of the plains and hilly areas (e.g. terraced fields) in the humid and subhumid regions, tree pollen percentages decrease and herb percentages increase substantially in surface samples, even after excluding distinctly cultivated taxa. It is easy to imagine that herbaceous taxa, such as Artemisia, Chenopodiaceae, Humulus, and weed-type Poaceae would expand after forest clearance and this will change the regional vegetation composition and relative pollen abundances (Ding et al., 2011; Li et al., 2015). It will also alter the pollen-climate relationships for many pollen taxa in the response models (St. Jacques et al., 2008). This alteration can be seen in the comparisons of RDA ordination (Fig. 3) and estimated WA optima and tolerances (Fig. 7) for 15 major taxa between the two datasets.

Selected pollen taxa can be separated into two tree and herb groups by contrasting their WA optima in the $\mathrm{N}$ - and $\mathrm{H}-$ 
Table 2. Summary performance statistics of the first three components of the weighted averaging partial least squares regression (WAPLS) for annual precipitation $\left(P_{\mathrm{ann}}\right)$ based on leave-one-out cross validation for the natural set $(\mathrm{N}$-set) and the human-induced set $(\mathrm{H}$-set). Coefficient of determination between predicted and observed $P_{\text {ann }}\left(R^{2}\right)$, root mean square error of prediction (RMSEP; mm), average bias (ave. bias) and maximum bias (max. bias), RMSEP change in percentage (\%Change), and $p$ value are given. The selected models are shown in bold.

\begin{tabular}{llrrrrrr}
\hline Datasets & Model & $R^{2}$ & RMSEP & Ave. bias & Max. bias & \%Change & $p$ value \\
\hline \multirow{2}{*}{ N-set } & WA-PLS Component 1 & 0.83 & 96.02 & -0.34 & 82.10 & - & - \\
& WA-PLS Component 2 & $\mathbf{0 . 8 6}$ & $\mathbf{8 9 . 2 4}$ & $\mathbf{1 . 1 0}$ & $\mathbf{7 2 . 9 8}$ & $-\mathbf{7 . 0 6}$ & $\mathbf{0 . 0 0 1}$ \\
& WA-PLS Component 3 & 0.86 & 87.92 & -0.25 & 64.53 & -1.48 & 0.098 \\
\hline \multirow{2}{*}{ H-set } & WA-PLS Component 1 & 0.58 & 108.32 & -1.39 & 218.50 & - & - \\
& WA-PLS Component 2 & $\mathbf{0 . 6 4}$ & $\mathbf{1 0 0 . 4 8}$ & $\mathbf{1 . 0 2}$ & $\mathbf{1 8 3 . 0 6}$ & $\mathbf{- 7 . 2 3}$ & $\mathbf{0 . 0 0 1}$ \\
& WA-PLS Component 3 & 0.64 & 100.84 & 0.99 & 177.97 & 0.36 & 0.614 \\
\hline
\end{tabular}
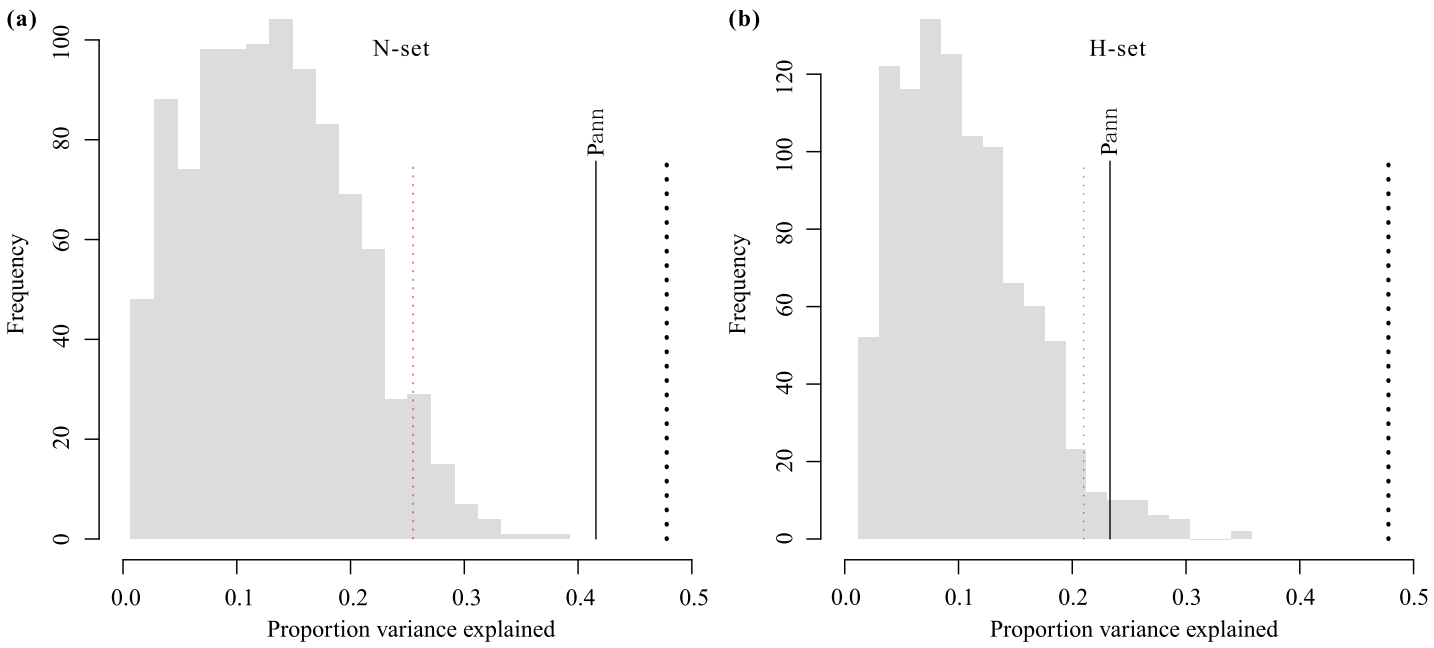

Figure 5. Proportion of variance (solid lines) in Gonghai Lake fossil pollen data explained by annual precipitation $\left(P_{\text {ann }}\right)$ transfer functions with (a) the natural set (N-set) and (b) the human-induced set (H-set). The thick black dotted lines indicate the proportion of variance explained by the first axis of a principal components analysis (PCA), and the fine red dotted lines indicate the 0.05 significance level. Histograms show the amount of variance explained by 999 transfer functions with random data.

sets (Fig. 7). The inferred optima of most woody taxa in the $\mathrm{H}$-set are shifted towards drier conditions and their tolerances compressed. This means that a fossil pollen assemblage with a high proportion of woody taxa would be assigned a lower $P_{\text {ann }}$ value when the H-set is employed in the transfer function. Conversely, $P_{\text {ann }}$ values will be overestimated when herbaceous taxa dominate in a fossil sample. This is clearly seen in the $P_{\text {ann }}$ curves for Lake Gonghai (Fig. 6a). The reconstructed $P_{\text {ann }}$ deviations between the N- and H-sets and the tree pollen percentage curve demonstrate similar trends (Fig. 6) and are statistically correlated $(R=0.81)$. However, the $P_{\text {ann }}$ deviation is not simply determined by the proportion of tree and herb taxa. For example, the deviations in (time window) TW2 and the later TW5 are both around zero, but the tree pollen comprises $20-30$ and $40-50 \%$, respectively, rather than being equal with the percentage of herbs. This is a consequence of the vegetation composition and species characteristics.
In short, human impact obscures the climatic signals in pollen spectra by distorting the response relationship between pollen abundance and climate (Birks et al., 2010; Seppä et al., 2004), thus influencing the assumed climatic optima and tolerances of pollen taxa in the model (Fig. 7). When such a human-influenced calibration set is applied to a fossil record, which represents mostly natural vegetation, a more or less serious bias in the reconstructed past climate should be expected (St. Jacques et al., 2008; Xu et al., 2010a). Using the $\mathrm{H}$-set in this study, significantly lower $(P<0.001)$ $P_{\text {ann }}$ values relative to the $\mathrm{N}$-set are reconstructed for Lake Gonghai during the early and middle Holocene (TW3 and TW4) when tree pollen contributed more than $40 \%$ to the total pollen sum. This suggests that drier biases may have also been induced from surface samples using the $\mathrm{N}$-set for this period. Conversely, we note a bias towards a wetter climate reconstruction for the late glacial (TW1) and the last 1600 years (TW6). The sites comprising the two sets, $\mathrm{N}$ and 


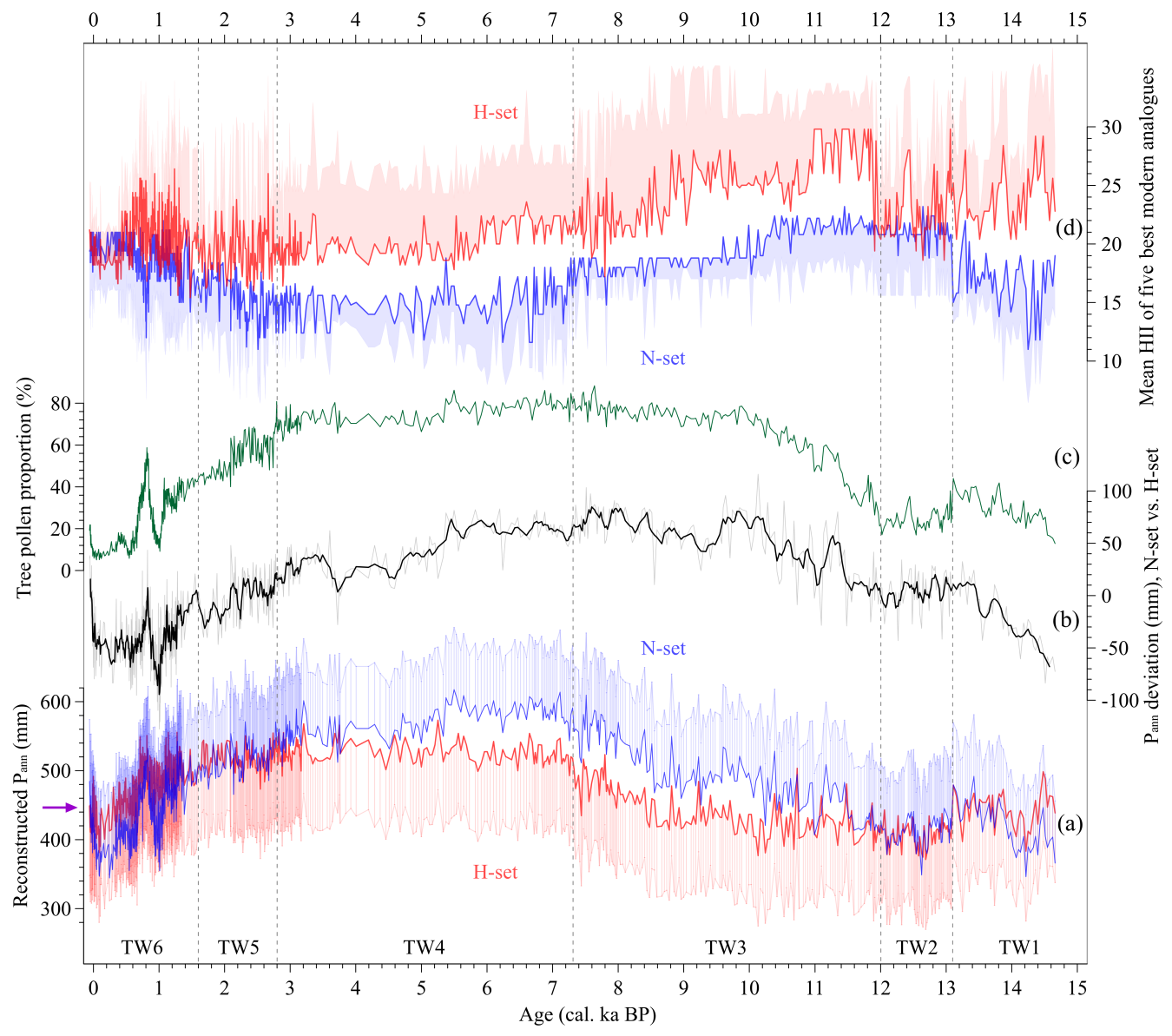

Figure 6. Fossil pollen record of Lake Gonghai: (a) reconstructed annual precipitation using a natural set (N-set; blue) with upper-side standard error of prediction (SEP) and a human-induced set (H-set; red) with lower-side SEP. The modern instrumental value is marked on the scale axis for comparison (purple arrow). (b) Deviations in the reconstructed precipitation (grey) between the $\mathrm{N}$-set- and $\mathrm{H}$-set-based transfer functions with a 5-point moving average smoother (black). (c) The proportion of tree pollen taxa (\%) and (d) the mean HII value of the five best analogues in the $\mathrm{N}$-set (blue, with lower-side standard deviation) and the H-set (red, with higher-side standard deviation) for fossil samples. Six time windows (TWs) delineated according to the deviation pattern between the two reconstructions are separated by grey dashed lines.

$\mathrm{H}$, are not perfectly even distributed, which may also influence the optima estimates (Fig. 1b). However, the modelinferred group-optima change pattern is statistically and ecologically reliable (Fig. 7). We consider it likely that a similar effect will occur in the pollen-based climate reconstructions for the whole TEC region where the vegetation pattern has been largely shaped by EASM-induced rainfall.

\subsection{Human influence index as an assessment tool}

Modern HIIs capture basic characteristics of human influence on ecosystems and allow for a quantitative evaluation of the human impact on the land surface (Sanderson et al., 2002). Li et al. (2014) innovatively employed an HII to establish a calibration set with pollen data and applied it to a 6200-year fossil record from Lake Tianchi in central China (Zhao et al., 2010). The pollen-HII calibration model $\left(R^{2}=\right.$
0.47) was based on 185 modern samples from central-eastern China (a warm temperate forest region), and the variance in the training set explained by HII $(6.79 \%)$ is comparable to $P_{\text {ann }}(7.78 \%)$ and $T_{\text {ann }}(6.00 \%$; Li et al., 2014). A further investigation based on 189 surface pollen samples from northern China (involving both human-induced and natural samples from vegetation regions II, III, and VI) provided a higher correlation $\left(R^{2}=0.69\right)$ between pollen and HII values in a WA-PLS model (Li et al., 2015). This good statistical performance gives us more confidence in assessing human influence on vegetation using the HII, although we are aware of some difficulties in applying a quantitative pollen-HII calibration model to the fossil data.

A good correlation of the HII data with cereal-type Poaceae pollen in northern China ( $\mathrm{Li}$ et al., 2015) suggests that the HII can be seen as a surrogate of indicator pollen taxa for human activities. However, cereal-type Poaceae pollen 


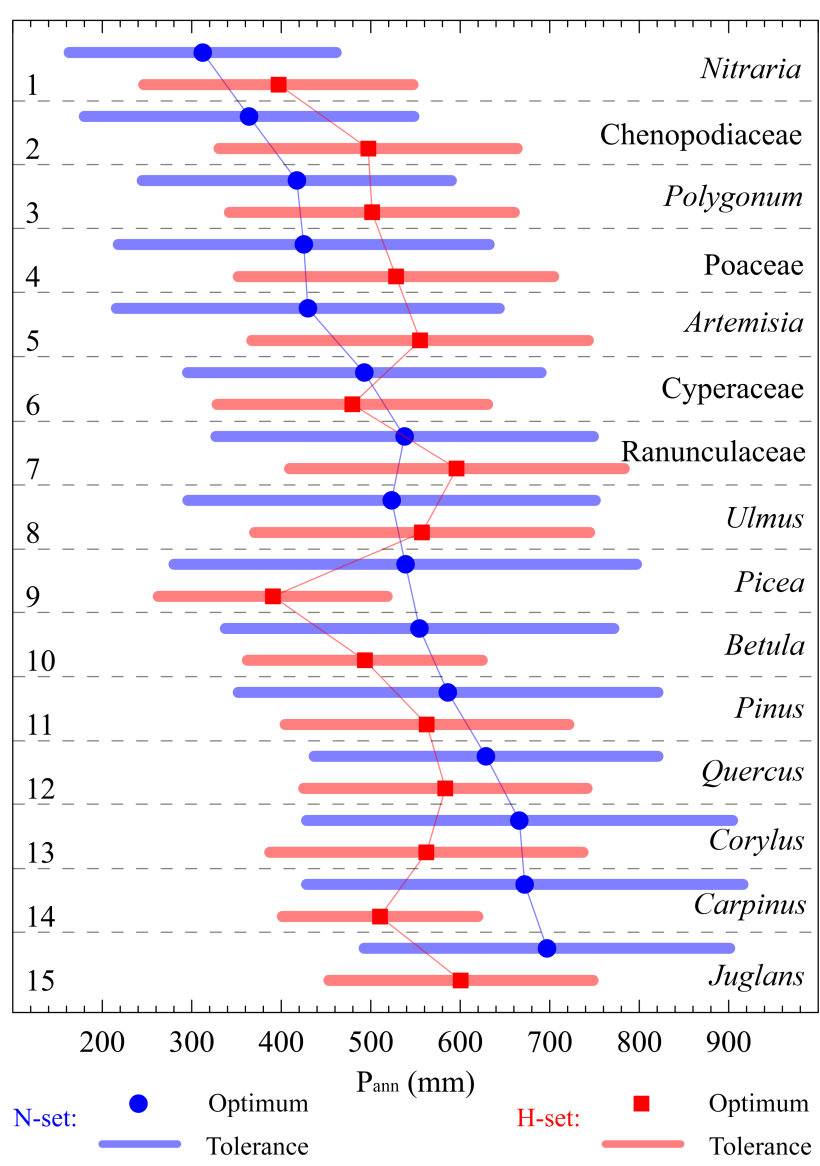

Figure 7. Caterpillar plot of weighted average (WA) optima and tolerances for 15 major pollen taxa in response to annual precipitation $\left(P_{\mathrm{ann}}\right)$. The taxa are arranged by optima values and taxa groups. Human impact generally shifts the inferred optima of woody taxa and herb taxa in opposite directions and compresses the tolerances for most taxa in the study area.

generally has a very low abundance in a fossil sequence. For example, the cereal-type Poaceae in a natural profile close to the archaeological sites from Anyang, the centre of agricultural and societal development during late Shang Dynasty, comprises only around $2 \%$ of the total pollen during the last 3400 years (Cao et al., 2010). In the sequence from Lake Gonghai used in the current study, it contributes about 2-4\% during the last 2 millennia (Fig. 2). Therefore, HII explains only $1.12 \%$ of the variance in the $\mathrm{N}$-set and $2.29 \%$ in the $\mathrm{H}$-set after removing the cereal-type Poaceae and other distinct cultivars (Table 1). In addition to cereal-type Poaceae, taxa such as Artemisia, Chenopodiaceae, and weed Poaceae, which could be dominant in both steppe areas and subhumid areas after forest clearance (Ding et al., 2011; Li et al., 2008; Liu et al., 2006), may challenge the interpretations. Although the human impact can be detected using additional information, including charcoal and archaeological data (Zhao et al., 2010), compositional changes in these taxa during the late
Holocene due to human activities are hard to distinguish from those caused by a progressively drier EASM climate, especially in fossil pollen records from the forest-steppe ecotone in TEC.

Reconstructing human influence quantitatively from fossil pollen data with a direct pollen-HII calibration set might not be an easy task in most cases ( $\mathrm{Li}$ et al., 2014), but we can still use HII as an assessment tool in a broad spectrum way. The reconstructed climate of a certain fossil sample is mostly determined by its closest modern analogues even though different approaches may have been used for the reconstruction (e.g. WA-PLS; Birks et al., 1990). By examining the mean HII values at sites of the best modern analogues, we can evaluate the bias in the climate reconstruction of the corresponding fossil sample. A high analogue HII value indicates greater potential bias in the reference samples. As shown in Fig. 6d, analogue HII values in the H-set are usually higher than in the N-set, suggesting a higher bias in the $P_{\text {ann }}$ reconstruction. The mean analogue HII values in the $\mathrm{N}$-set fluctuate at around 15 during the mid-Holocene, indicating that the climate reconstruction for this interval has the lowest humaninduced bias as an HII value of 15 is the mean background value for modern natural vegetation patches in TEC ( $\mathrm{Li}$ et al., 2015; Sanderson et al., 2002). Similar to the HII trend in Lake Tianchi (Li et al., 2014), analogue HII values for Lake Gonghai start to rise around 2.8-2.9 ka BP, which conforms to the scenario of agricultural advancements and population growth in Bronze Age China during the Western Zhou period (1045-771 BC; Li, 2006). Relatively higher analogue HII values during the late glacial and early Holocene suggest that modern analogues for this period in the current reference dataset have experienced more human influence. Together with the common problem of no analogues for this period (Jackson and Williams, 2004), climate reconstructions for this interval in TEC should also be considered more carefully.

\subsection{Implications for Holocene climate reconstructions}

Agriculture became the dominant subsistence strategy in today's (potentially) warm temperate forest region (III, including the central China Plains) and northern subtropical mixed forest zone (IVAi, including the Yangtze Plains) from about 6.5-5 ka BP (Crawford, 2011; Zhao, 2010). Potential human disturbance to the vegetation in eastern China since $6 \mathrm{ka} \mathrm{BP}$ has been inferred from many pollen studies (Ren and Beug, 2002; Wang et al., 2010), not to mention historical times (Cao et al., 2010; Zhao et al., 2010). Our analogue HII assessments indicate that the bias in the climate reconstruction induced from human impact via reference pollen samples or via changes in the fossil pollen assemblages (particularly during historical times; Li et al., 2014) is real. This raises the question of whether the Holocene climate could be quantitatively reconstructed using pollen data from eastern China. The answer is not a simple yes or no (Ren and Beug, 2002), 
although we keep an optimistic view based on the comparison results presented in this study.

Reconstructed $P_{\text {ann }}$ for the uppermost 17 samples from the Gonghai record, representing AD 1950-2008, is $428 \mathrm{~mm}$ $(\mathrm{SD}=26 \mathrm{~mm})$ with the $\mathrm{N}$-set and $439 \mathrm{~mm}(\mathrm{SD}=25 \mathrm{~mm})$ with the $\mathrm{H}$-set. The modern mean $P_{\text {ann }}$ around the Lake Gonghai area is $445 \mathrm{~mm}$ according to instrumental data between 1959 and 2011 from Ningwu station, located $11 \mathrm{~km}$ north of the lake (Chen et al., 2015). Both calibration sets provide reliable (more or less similar) reconstructions for recent decades when compared with historical measurements, although deviations consistently exist since the last deglaciation (Fig. 6). By examining the deviation range between the two datasets, and bearing in mind that surface reference samples in the $\mathrm{H}$-set are more or less strongly affected by human activities, we can assume that the $P_{\text {ann }}$ reconstruction based on the N-set should be closer to reality. Holocene pollenclimate relationships in China are relatively stable (Tian et al., 2017). If we select appropriate sites, such as Tianchi and Gonghai lakes, both of which are small closed alpine lakes with very limited human impact before $3 \mathrm{ka} \mathrm{BP}$ (Institute of Archaeology CASS, 2004, 2003), we can still hope to get a reliable $P_{\text {ann }}$ reconstruction prior to the late Holocene. Our Holocene $P_{\text {ann }}$ reconstruction using the N-set can further the discussion on cultural evolution and the origin of dry-land agriculture in the study region. For example, a remarkable $P_{\text {ann }}$ increase from 480 to $570 \mathrm{~mm}$ along the present-day EASM margin during 8.6-7.8 ka BP could have promoted the development of millet agriculture (Liu et al., 2012; Zhao, 2011). It also supports the hypothesis that at early Neolithic sites broomcorn millet (low $P_{\text {ann }}$ requirement: $350-450 \mathrm{~mm}$ ) is more abundant than foxtail millet (optima: $450-550 \mathrm{~mm}$ ) as broomcorn millet is better adapted to drought conditions (Lu et al., 2009).

Regarding the potential human-induced bias in fossil records, the challenge for pollen-based quantitative climate reconstructions is more from the lack of natural surface samples in regions with intensive agricultural activities. In eastern China, a calibration set only including preferenced pollen samples from lake surface sediments with low human disturbance is still not available (Liu et al., 2013), and surface samples are mostly collected from mountains and steppe areas (Xu et al., 2010b). This means that our current modern pollen datasets (Cao et al., 2014; Zheng et al., 2014) still contain relatively few samples from central-eastern China. Collecting extra samples from natural vegetation in mountain areas, such as Luzhong, Qin, Dabie, and Qian, would help to improve the pollen-based climate reconstructions for the region. The Qin Mountains, for example, have a large and well-forested range (ca. $57000 \mathrm{~km}^{2}$ ) but are represented by relatively few pollen samples (Fig. 1b). In addition, there are still hundreds of small forests (patches) in the hilly areas, around the lakes, and within natural parks in eastern China which deserve the attention of palynologists.

\section{Conclusions}

This paper attempts to assess the extent of bias induced from human impact in pollen-based quantitative climate reconstructions. Numerical analyses suggest that $P_{\mathrm{ann}}$ is the main explanatory variable for pollen distribution in temperate eastern China, even in the pollen dataset with intense human impact. The model-inferred $P_{\text {ann }}$ optima of most major woody pollen taxa in the human-induced dataset shift to the arid end of the gradient, resulting in the underestimation of $P_{\mathrm{ann}}$ when the percentages of tree pollen are high in the fossil record. In the context of long-term human impact on vegetation in the study region, a bias in pollen-based climate reconstructions is inevitable. However, our study demonstrates how this bias manifests and how a more reliable $P_{\text {ann }}$ reconstruction can be inferred from the fossil pollen record. Reconstructed $P_{\text {ann }}$ using the natural dataset in this study reliably portrays the Holocene monsoon rainfall variations in northern China and supports a valid interpretation of the dry-land agriculture origin in the region. Our research also indicates that climate reconstructions should be conducted with caution, particularly for the last 1 or 2 millennia when population pressure is high and land use is intensive. Other sources of evidence, including archaeological or historical data, are helpful (and absolutely necessary) for a more accurate interpretation of results.

Data availability. Supplementary data are available at https://doi. pangaea.de/10.1594/PANGAEA.880993 in the Pangaea database.

Competing interests. The authors declare that they have no conflict of interest.

Acknowledgements. We are grateful to Chunhai Li for his pollen analyses of samples from the Jiangsu coastal plain and Cathy Jenks for her linguistic help. This work was supported by the key programmes of the National Natural Science Foundation of China (40730103 and 41630753). The doctoral research of Wei Ding at Freie Universität Berlin in the working group of Pavel E. Tarasov was funded by the China Scholarship Council (2011813072).

Edited by: Dominik Fleitmann

Reviewed by: two anonymous referees

\section{References}

Bartlein, P. J., Harrison, S. P., Brewer, S., Connor, S., Davis, B. A. S., Gajewski, K., Guiot, J., Harrison-Prentice, T. I., Henderson, A., Peyron, O., Prentice, I. C., Scholze, M., Seppä, H., Shuman, B., Sugita, S., Thompson, R. S., Viau, A. E., Williams, J., and Wu, H.: Pollen-based continental climate reconstructions at 6 and 21 ka: a global synthesis, Clim. Dynam., 37, 775-802, 2010. 
Bestel, S., Crawford, G. W., Liu, L., Shi, J., Song, Y., and Chen, X.: The evolution of millet domestication, Middle Yellow River Region, North China: Evidence from charred seeds at the late Upper Paleolithic Shizitan Locality 9 site, Holocene, 24, 261265, 2014

Birks, H. J. B.: Numerical tools in palaeolimnology - Progress, potentialities, and problems, J. Paleolimnol., 20, 307-332, 1998.

Birks, H. J. B. and Seppä, H.: Pollen-based reconstructions of lateQuaternary climate in Europe-progress, problems, and pitfalls, Acta Palaeobot., 44, 317-334, 2004.

Birks, H. J. B., Line, J. M., Juggins, S., Stevenson, A. C., and Terbraak, C. J. F.: Diatoms and pH Reconstruction, Philos. T. R. Soc. B, 327, 263-278, 1990.

Birks, H. J. B., Heiri, O., Seppä, H., and Bjune, A. E.: Strengths and weaknesses of quantitative climate reconstructions based on Late-Quaternary biological proxies, The Open Ecology Journal, 3, 68-110, 2010.

Cao, X., Xu, Q., Jing, Z., Tang, J., Li, Y., and Tian, F.: Holocene climate change and human impacts implied from the pollen records in Anyang, central China, Quaternary Int., 227, 3-9, 2010.

Cao, X., Ni, J., Herzschuh, U., Wang, Y., and Zhao, Y.: A late Quaternary pollen dataset from eastern continental Asia for vegetation and climate reconstructions: Set up and evaluation, Rev. Palaeobot. Palynol., 194, 21-37, 2013.

Cao, X., Herzschuh, U., Telford, R. J., and Ni, J.: A modern pollenclimate dataset from China and Mongolia: Assessing its potential for climate reconstruction, Rev. Palaeobot. Palynol., 211, 87-96, 2014.

Chen, F., Xu, Q., Chen, J., Birks, H. J., Liu, J., Zhang, S., Jin, L., An, C., Telford, R. J., Cao, X., Wang, Z., Zhang, X., Selvaraj, K., Lu, H., Li, Y., Zheng, Z., Wang, H., Zhou, A., Dong, G., Zhang, J., Huang, X., Bloemendal, J., and Rao, Z.: East Asian summer monsoon precipitation variability since the last deglaciation, Sci. Rep., 5, 11186, https://doi.org/10.1038/srep11186, 2015.

Crawford, G.: Early rice exploitation in the lower Yangzi valley: What are we missing?, Holocene, 22, 613-621, 2011.

Ding, W., Pang, R., Xu, Q., Li, Y., and Cao, X.: Surface pollen assemblages as indicators of human impact in the warm temperate hilly areas of eastern China, Chinese Sci. Bull., 56, 996-1004, 2011.

Domrös, M. and Peng, G.: The Climate of China, Springer, Berlin, 1988.

Editorial Committee of Vegetation Map of China, CAS: Vegetation map of the People's Republic of China (1:1000 000), Geological Publishing House, Beijing, 2007.

Fu, C., Jiang, Z., Guan, Z., He, J., and Xu, Z. (Eds.): Regional climate studies of China, Springer, Berlin, 2008.

Grimm, E. C.: CONISS: a FORTRAN 77 program for stratigraphically constrained cluster analysis by the method of incremental sum of squares, Comput. Geosci., 13, 13-35, 1987.

Grimm, E. C.: Tilia 1.7. 16, in: Illinois State Museum, Research and Collection Center, Springfield, 2011.

Guiot, J.: Methodology of the last climatic cycle reconstruction in France from pollen data, Palaeogeogr. Palaeocl., 80, 49-69, 1990.

Guiot, J., Hai Bin Wu, Wen Ying Jiang, and Yun Li Luo: East Asian Monsoon and paleoclimatic data analysis: a vegetation point of view, Clim. Past, 4, 137-145, https://doi.org/10.5194/cp-4-1372008, 2008.
Guiot, J., Wu, H. B., Garreta, V., Hatté, C., and Magny, M.: A few prospective ideas on climate reconstruction: from a statistical single proxy approach towards a multi-proxy and dynamical approach, Clim. Past, 5, 571-583, https://doi.org/10.5194/cp-5571-2009, 2009.

Herzschuh, U., Birks, H. J. B., Mischke, S., Zhang, C., and Böhner, J.: A modern pollen-climate calibration set based on lake sediments from the Tibetan Plateau and its application to a Late Quaternary pollen record from the Qilian Mountains, J. Biogeogr., 37, 752-766, 2010.

Hill, M. O. and Gauch, H. G.: Detrended correspondence analysis: An improved ordination technique, Vegetatio, 42, 47-58, 1980.

Imbrie, J. and Kipp, N. G.: A new micropaleontological method for quantitative paleoclimatology: application to a late Pleistocene Caribbean core, in: The late Cenozoic glacial ages, edited by: Turekian, K. K., Yale University Press, New Haven, 1971.

Institute of Archaeology CASS: Chinese Archaeology: Xia and Shang, China Social Sciences Press, Beijing, 2003 (in Chinese).

Institute of Archaeology CASS: Chinese Archaeology: Western Zhou and Eastern Zhou, China Social Sciences Press, Beijing, 2004 (in Chinese).

Jackson, S. T. and Williams, J. W.: Modern analogs in Quaternary palaeoecology: Here today, gone yesterday, gone tomorrow?, Annu. Rev. Earth Pl. Sc., 32, 495-537, 2004.

Juggins, S.: Quantitative reconstructions in palaeolimnology: new paradigm or sick science?, Quaternary Sci. Rev., 64, 20-32, 2013.

Juggins, S.: rioja: Analysis of Quaternary Science Data, available at: http://cran.r-project.org/package=rioja, 2015.

Juggins, S. and Birks, H. J. B.: Quantitative environmental reconstructions from biological data, in: Tracking Environmental Change Using Lake Sediments, Vol. 5: Data Handling and Numerical Techniques, edited by: Birks, J. B. H., Lotter, A. F., Juggins, S., and Smol, J. P., Springer Netherlands, Dordrecht, 2012.

Li, F.: Landscape and power in early China: the crisis and fall of the Western Zhou 1045-771 BC, Cambridge University Press, Cambridge, 2006.

Li, J., Zhao, Y., Xu, Q., Zheng, Z., Lu, H., Luo, Y., Li, Y., Li, C., and Seppä, H.: Human influence as a potential source of bias in pollen-based quantitative climate reconstructions, Quaternary Sci. Rev., 99, 112-121, 2014.

Li, M., Li, Y., Xu, Q., Pang, R., Ding, W., Zhang, S., and He, Z.: Surface pollen assemblages of human-disturbed vegetation and their relationship with vegetation and climate in Northeast China, Chinese Sci. Bull., 57, 535-547, 2012.

Li, M., Xu, Q., Zhang, S., Li, Y., Ding, W., and Li, J.: Indicator pollen taxa of human-induced and natural vegetation in Northern China, Holocene, 25, 686-701, 2015.

Li, Y., Zhou, L., and Cui, H.: Pollen indicators of human activity, Chinese Sci. Bull., 53, 1281-1293, 2008.

Li, Y., Xu, Q., Zhang, L., Wang, X., Cao, X., and Yang, X.: Modern pollen assemblages of the forest communities and their relationships with vegetation and climate in northern China, J. Geogr. Sci., 19, 643-659, 2009.

Liu, G., Yin, Y., Liu, H., and Hao, Q.: Quantifying regional vegetation cover variability in North China during the Holocene: implications for climate feedback, PLoS One, 8, e71681, https://doi.org/10.1371/journal.pone.0071681, 2013. 
Liu, H., Wang, Y., Tian, Y., Zhu, J., and Wang, H.: Climatic and anthropogenic control of surface pollen assemblages in East Asian steppes, Rev. Palaeobot. Palynol., 138, 281-289, 2006.

Liu, H., Yin, Y., Hao, Q., and Liu, G.: Sensitivity of temperate vegetation to Holocene development of East Asian monsoon, Quaternary Sci. Rev., 98, 126-134, 2014.

Liu, L., Duncan, N. A., Chen, X., Liu, G., and Zhao, H.: Plant domestication, cultivation, and foraging by the first farmers in early Neolithic Northeast China: Evidence from microbotanical remains, Holocene, 25, 1965-1978, 2015.

Liu, X., Jones, M. K., Zhao, Z., Liu, G., and O'Connell, T. C.: The earliest evidence of millet as a staple crop: New light on neolithic foodways in North China, Am. J. Phys. Anthropol., 149, 283290, 2012.

Lu, H., Zhang, J., Liu, K. B., Wu, N., Li, Y., Zhou, K., Ye, M., Zhang, T., Zhang, H., Yang, X., Shen, L., Xu, D., and Li, Q.: Earliest domestication of common millet (Panicum miliaceum) in East Asia extended to 10,000 years ago, P. Natl. Acad. Sci. USA, 106, 7367-7372, 2009.

Lu, H. Y., Wu, N. Q., Liu, K. B., Zhu, L. P., Yang, X. D., Yao, T. D., Wang, L., Li, Q. A., Liu, X. Q., Shen, C. M., Li, X. Q., Tong, G. B., and Jiang, H.: Modern pollen distributions in QinghaiTibetan Plateau and the development of transfer functions for reconstructing Holocene environmental changes, Quaternary Sci. Rev., 30, 947-966, 2011.

Luo, C., Zheng, Z., Tarasov, P., Pan, A., Huang, K., Beaudouin, C., and An, F.: Characteristics of the modern pollen distribution and their relationship to vegetation in the Xinjiang region, northwestern China, Rev. Palaeobot. Palynol., 153, 282-295, 2009.

Ma, Y., Xu, Q., Huang, X., Zhou, G., Zhang, L., Tao, S., and Sun, H.: Pollen assemblage characters of human disturbed vegetation in arid area in northwestern China, J. Palaeogeogr., 11, 542-550, 2009 (in Chinese).

Markgraf, V., Webb, R. S., Anderson, K. H., and Anderson, L.: Modern pollen/climate calibration for southern South America, Palaeogeogr. Palaeocl., 181, 375-397, 2002.

Marquer, L., Gaillard, M.-J., Sugita, S., Trondman, A.-K., Mazier, F., Nielsen, A. B., Fyfe, R. M., Odgaard, B. V., Alenius, T., Birks, H. J. B., Bjune, A. E., Christiansen, J., Dodson, J., Edwards, K. J., Giesecke, T., Herzschuh, U., Kangur, M., Lorenz, S., Poska, A., Schult, M., and Seppä, H.: Holocene changes in vegetation composition in northern Europe: why quantitative pollen-based vegetation reconstructions matter, Quaternary Sci. Rev., 90, 199216, 2014.

Mu, H., Xu, Q., Zhang, S., Hun, L., Li, M., Li, Y., Hu, Y., and Xie, F.: Pollen-based quantitative reconstruction of the paleoclimate during the formation process of Houjiayao Relic Site in Nihewan Basin of China, Quaternary Int., 374, 76-84, 2015.

Ni, J., Cao, X., Jeltsch, F., and Herzschuh, U.: Biome distribution over the last 22,000 yr in China, Palaeogeogr. Palaeocl., 409, 3347, 2014.

Oksanen, J., Blanchet, F. G., Kindt, R., Legendre, P., Minchin, P. R., O'Hara, R. B., Simpson, G. L., Solymos, P., Stevens, M. H. H., and Wagner, H.: vegan: Community Ecology Package, available at: https://CRAN.R-project.org/package=vegan, 2016.

Overpeck, J. T., Webb, T., and Prentice, I. C.: Quantitative interpretation of fossil pollen spectra: Dissimilarity coefficients and the method of modern analogs, Quaternary Res., 23, 87-108, 1985.
Pang, R., Xu, Q., Ding, W., and Zhang, S.: Pollen assemblages of cultivated vegetation in central and southern Hebei Province, J. Geogr. Sci., 21, 549-560, 2011.

Parnell, A. C., Haslett, J., Sweeney, J., Doan, T. K., Allen, J. R. M., and Huntley, B.: Joint palaeoclimate reconstruction from pollen data via forward models and climate histories, Quaternary Sci. Rev., 151, 111-126, 2016.

Prentice, I. C.: Multidimensional scaling as a research tool in quaternary palynology: A review of theory and methods, Rev. Palaeobot. Palynol., 31, 71-104, 1980.

Prentice, I. C., Jolly, D., and BIOME 6000 participants: MidHolocene and glacial-maximum vegetation geography of the northern continents and Africa, J. Biogeogr., 27, 507-519, 2000.

R Core Team: R: A Language and Environment for Statistical Computing, R Foundation for Statistical Computing, Vienna, Austria, 2016.

Ren, G.: Decline of the mid- to late Holocene forests in China: climatic change or human impact?, J. Quaternary Sci., 15, 273-281, 2000.

Ren, G. and Beug, H.-J.: Mapping Holocene pollen data and vegetation of China, Quaternary Sci. Rev., 21, 1395-1422, 2002.

Ruddiman, W. F.: The anthropogenic greenhouse era began thousands of years ago, Climatic Change, 61, 261-293, 2003.

Sanderson, E. W., Jaiteh, M., Levy, M. A., Redford, K. H., Wannebo, A. V., and Woolmer, G.: The human footprint and the last of the wild, Bioscience, 52, 891-904, 2002.

Scott, G. H.: Uniformitarianism, the uniformity of nature, and paleoecology, N.Z. J. Geol. Geophys., 6, 510-527, 1963.

Seppä, H., Birks, H. J. B., Odland, A., Poska, A., and Veski, S.: A modern pollen-climate calibration set from northern Europe: developing and testing a tool for palaeoclimatological reconstructions, J. Biogeogr., 31, 251-267, 2004.

Shen, C., Liu, K.-B., Tang, L., and Overpeck, J. T.: Quantitative relationships between modern pollen rain and climate in the Tibetan Plateau, Rev. Palaeobot. Palynol., 140, 61-77, 2006.

Simpson, G. L.: Analogue Methods in Palaeoecology: Using the analogue Package, J. Stat. Softw., 22, 1-29, 2007.

St. Jacques, J. M., Cumming, B. F., and Smol, J. P.: A pre-European settlement pollen-climate calibration set for Minnesota, USA: developing tools for palaeoclimatic reconstructions, J. Biogeogr., 35, 306-324, 2008.

St. Jacques, J. M., Cumming, B. F., Sauchyn, D. J., and Smol, J. P.: The bias and signal attenuation present in conventional pollen-based climate reconstructions as assessed by early climate data from Minnesota, USA, PLoS One, 10, e0113806, https://doi.org/10.1371/journal.pone.0113806, 2015.

Sun, X., Song, C., and Chen, X.: China Quaternary pollen database (CPD) and Biome 6000 project, Adv. Earth Sci., 14, 407-411, 1999.

Tarasov, P., Granoszewski, W., Bezrukova, E., Brewer, S., Nita, M., Abzaeva, A., and Oberhänsli, H.: Quantitative reconstruction of the last interglacial vegetation and climate based on the pollen record from Lake Baikal, Russia, Clim. Dynam., 25, 625-637, 2005.

Tarasov, P., Jin, G., and Wagner, M.: Mid-Holocene environmental and human dynamics in northeastern China reconstructed from pollen and archaeological data, Palaeogeogr. Palaeocl., 241, 284-300, 2006. 
Tarasov, P. E., Webb Iii, T., Andreev, A. A., Afanas'eva, N. B., Berezina, N. A., Bezusko, L. G., Blyakharchuk, T. A., Bolikhovskaya, N. S., Cheddadi, R., Chernavskaya, M. M., Chernova, G. M., Dorofeyuk, N. I., Dirksen, V. G., Elina, G. A., Filimonova, L. V., Glebov, F. Z., Guiot, J., Gunova, V. S., Harrison, S. P., Jolly, D., Khomutova, V. I., Kvavadze, E. V., Osipova, I. M., Panova, N. K., Prentice, I. C., Saarse, L., Sevastyanov, D. V., Volkova, V. S., and Zernitskaya, V. P.: Present-day and midHolocene biomes reconstructed from pollen and plant macrofossil data from the former Soviet Union and Mongolia, J. Biogeogr., 25, 1029-1053, 1998.

Tarasov, P. E., Peyron, O., Guiot, J., Brewer, S., Volkova, V. S., Bezusko, L. G., Dorofeyuk, N. I., Kvavadze, E. V., Osipova, I. M., and Panova, N. K.: Last Glacial Maximum climate of the former Soviet Union and Mongolia reconstructed from pollen and plant macrofossil data, Clim. Dynam., 15, 227-240, 1999.

Tarasov, P. E., Nakagawa, T., Demske, D., Österle, H., Igarashi, Y., Kitagawa, J., Mokhova, L., Bazarova, V., Okuda, M., Gotanda, K., Miyoshi, N., Fujiki, T., Takemura, K., Yonenobu, H., and Fleck, A.: Progress in the reconstruction of Quaternary climate dynamics in the Northwest Pacific: A new modern analogue reference dataset and its application to the 430-kyr pollen record from Lake Biwa, Earth Sci. Rev., 108, 64-79, 2011.

Telford, R. J.: palaeoSig: Significance Tests of Quantitative Palaeoenvironmental Reconstructions, available at: http://cran. r-project.org/package=palaeoSig, 2015.

Telford, R. J. and Birks, H. J. B.: A novel method for assessing the statistical significance of quantitative reconstructions inferred from biotic assemblages, Quaternary Sci. Rev., 30, 1272-1278, 2011

ter Braak, C. J. F.: The analysis of vegetation-environment relationships by canonical correspondence analysis, Vegetatio, 69, 6977, 1987.

ter Braak, C. J. F. and Juggins, S.: Weighted averaging partial least squares regression (WA-PLS): an improved method for reconstructing environmental variables from species assemblages, Hydrobiologia, 269-270, 485-502, 1993.

ter Braak, C. J. F. and Looman, C. W. N.: Weighted averaging, logistic regression and the Gaussian response model, Vegetatio, 65, 3-11, 1986.

ter Braak, C. J. F. and Prentice, I. C.: A theory of gradient analysis, Adv. Ecol. Res., 18, 271-317, 1988.

Tian, F., Cao, X., Dallmeyer, A., Ni, J., Zhao, Y., Wang, Y., and Herzschuh, U.: Quantitative woody cover reconstructions from eastern continental Asia of the last $22 \mathrm{kyr}$ reveal strong regional peculiarities, Quaternary Sci. Rev., 137, 33-44, 2016.

Tian, F., Cao, X., Dallmeyer, A., Zhao, Y., Ni, J., and Herzschuh, U.: Pollen-climate relationships in time (9 ka, $6 \mathrm{ka}, 0 \mathrm{ka})$ and space (upland vs. lowland) in eastern continental Asia, Quaternary Sci. Rev., 156, 1-11, 2017.

van der Voet, H.: Comparing the predictive accuracy of models using a simple randomization test, Chemometrics Intellig. Lab. Syst., 25, 313-323, 1994.

von Post, L.: Einige südschwedischen Quellmoore, Bulletin of the Geological Institution of the University of Upsala, 15, 219-278, 1916.

Wang, X., Li, Y., Xu, Q., Cao, X., Zhang, L., and Tian, F.: Pollen assemblages from different agricultural units and their spatial distribution in Anyang area, Chinese Sci. Bull., 55, 544-554, 2009.
Wang, Y., Liu, X., and Herzschuh, U.: Asynchronous evolution of the Indian and East Asian Summer Monsoon indicated by Holocene moisture patterns in monsoonal central Asia, Earth Sci. Rev., 103, 135-153, 2010.

Wang, Y., Herzschuh, U., Shumilovskikh, L. S., Mischke, S., Birks, H. J. B., Wischnewski, J., Böhner, J., Schlütz, F., Lehmkuhl, F., Diekmann, B., Wünnemann, B., and Zhang, C.: Quantitative reconstruction of precipitation changes on the NE Tibetan Plateau since the Last Glacial Maximum - extending the concept of pollen source area to pollen-based climate reconstructions from large lakes, Clim. Past, 10, 21-39, https://doi.org/10.5194/cp-1021-2014, 2014.

Wen, R., Xiao, J., Ma, Y., Feng, Z., Li, Y., and Xu, Q.: Pollenclimate transfer functions intended for temperate eastern Asia, Quaternary Int., 311, 3-11, 2013.

Whitmore, J., Gajewski, K., Sawada, M., Williams, J. W., Shuman, B., Bartlein, P. J., Minckley, T., Viau, A. E., Webb, T., Shafer, S., Anderson, P., and Brubaker, L.: Modern pollen data from North America and Greenland for multi-scale paleoenvironmental applications, Quaternary Sci. Rev., 24, 1828-1848, 2005.

Wu, Z., Raven, P. H., and Hong, D. (Eds.): Flora of China, Science Press, Beijing, 2013.

Xiao, J., Xu, Q., Nakamura, T., Yang, X., Liang, W., and Inouchi, Y.: Holocene vegetation variation in the Daihai Lake region of north-central China: a direct indication of the Asian monsoon climatic history, Quaternary Sci. Rev., 23, 1669-1679, 2004.

Xu, Q., Li, Y., Yang, X., and Zheng, Z.: Quantitative relationship between pollen and vegetation in northern China, Sci. China Ser. D, 50, 582-599, 2007.

Xu, Q., Li, Y., Bunting, M. J., Tian, F., and Liu, J.: The effects of training set selection on the relationship between pollen assemblages and climate parameters: Implications for reconstructing past climate, Palaeogeogr. Palaeocl., 289, 123-133, 2010a.

Xu, Q. H., Xiao, J. L., Li, Y. C., Tian, F., and Nakagawa, T.: Pollenbased quantitative reconstruction of Holocene climate changes in the Daihai Lake area, Inner Mongolia, China, J. Climate, 23, 2856-2868, 2010b.

Xu, Q., Chen, F., Zhang, S., Cao, X., Li, J., Li, Y., Li, M., Chen, J., Liu, J., and Wang, Z.: Vegetation succession and East Asian Summer Monsoon Changes since the last deglaciation inferred from high-resolution pollen record in Gonghai Lake, Shanxi Province, China, Holocene, 27, 835-846, 2016 a.

Xu, Q., Zhang, S., Gaillard, M.-J., Li, M., Cao, X., Tian, F., and Li, F.: Studies of modern pollen assemblages for pollen dispersaldeposition-preservation process understanding and for pollenbased reconstructions of past vegetation, climate, and human impact: A review based on case studies in China, Quaternary Sci. Rev., 149, 151-166, 2016b.

Yang, S., Zheng, Z., Huang, K., Zong, Y., Wang, J., Xu, Q., Rolett, B. V., and Li, J.: Modern pollen assemblages from cultivated rice fields and rice pollen morphology: Application to a study of ancient land use and agriculture in the Pearl River Delta, China, Holocene, 22, 1393-1404, 2012.

Yu, G., Prentice, I. C., Harrison, S. P., and Sun, X. J.: Pollen-based biome reconstructions for China at 0 and 6000 years, J. Biogeogr., 25, 1055-1069, 1998.

Yu, G., Chen, X., Ni, J., Cheddadi, R., Guiot, J., Han, H., Harrison, S. P., Huang, C., Ke, M., Kong, Z., Li, S., Li, W., Liew, P., Liu, G., Liu, J., Liu, Q., Liu, K. B., Prentice, I. C., Qui, W., Ren, G., Song, 
C., Sugita, S., Sun, X., Tang, L., VanCampo, E., Xia, Y., Xu, Q., Yan, S., Yang, X., Zhao, J., and Zheng, Z.: Palaeovegetation of China: a pollen data-based synthesis for the mid-Holocene and last glacial maximum, J. Biogeogr., 27, 635-664, 2000.

Zhang, S., Xu, Q., Nielsen, A. B., Chen, H., Li, Y., Li, M., Hun, L., and Li, J.: Pollen assemblages and their environmental implications in the Qaidam Basin, NW China, Boreas, 41, 602-613, 2012.

Zhang, W., Li, C., Lu, H., Tian, X., Zhang, H., Lei, F., and Tang, L.: Relationship between surface pollen assemblages and vegetation in Luonan Basin, Eastern Qinling Mountains, Central China, J. Geogr. Sci., 24, 427-445, 2014.

Zhang, Y., Kong, Z. C., Wang, G. H., and Ni, J.: Anthropogenic and climatic impacts on surface pollen assemblages along a precipitation gradient in north-eastern China, Global Ecol. Biogeogr., 19, 621-631, 2010.

Zhao, Y., Yu, Z., Chen, F., Zhang, J., and Yang, B.: Vegetation response to Holocene climate change in monsoon-influenced region of China, Earth Sci. Rev., 97, 242-256, 2009.

Zhao, Y., Chen, F., Zhou, A., Yu, Z., and Zhang, K.: Vegetation history, climate change and human activities over the last 6200 years on the Liupan Mountains in the southwestern Loess Plateau in central China, Palaeogeogr. Palaeocl., 293, 197-205, 2010.
Zhao, Z.: New data and new issues for the study of origin of rice agriculture in China, Archaeol. Anthropol. Sci., 2, 99-105, 2010.

Zhao, Z.: New archaeobotanic data for the study of the origins of agriculture in China, Curr. Anthropol., 52, S295-S306, 2011.

Zhao, Z. and Piperno, D. R.: Late Pleistocene/Holocene environments in the middle Yangtze River Valley, China and rice (Oryza sativa L.) domestication: The phytolith evidence, Geoarchaeology, 15, 203-222, 2000.

Zheng, Z., Huang, K., Xu, Q., Lu, H., Cheddadi, R., Luo, Y., Beaudouin, C., Luo, C., Zheng, Y., Li, C., Wei, J., and Du, C.: Comparison of climatic threshold of geographical distribution between dominant plants and surface pollen in China, Sci. China Ser. D, 51, 1107-1120, 2008.

Zheng, Z., Wei, J., Huang, K., Xu, Q., Lu, H., Tarasov, P., Luo, C., Beaudouin, C., Deng, Y., Pan, A., Zheng, Y., Luo, Y., Nakagawa, T., Li, C., Yang, S., Peng, H., Cheddadi, R., and Williams, J.: East Asian pollen database: modern pollen distribution and its quantitative relationship with vegetation and climate, J. Biogeogr., 41, 1819-1832, 2014. 